\title{
A simple RNA preparation method for SARS-CoV-2 detection by RT- qPCR
}

Aniela Wozniak ${ }^{1, \$}$, Ariel Cerda ${ }^{2, \$}$, Catalina Ibarra-Henriquez ${ }^{2, \$}$, Valentina Sebastian ${ }^{3}$, Grace Armijo ${ }^{2}$, Liliana Lamig ${ }^{2}$, Carolina Miranda ${ }^{3}$, Marcela Lagos ${ }^{1}$, Sandra Solari ${ }^{1}$, Ana María Guzmán ${ }^{1}$, Teresa Quiroga ${ }^{1}$, Susan Hitschfeld ${ }^{2}$, Eleodoro Riveras ${ }^{2}$, Marcela Ferres $^{1,4}$, Rodrigo A. Gutiérrez $z^{2, *}$ and Patricia García ${ }^{1, *}$

1. Departamento de Laboratorios Clínicos. Escuela de Medicina. Facultad de Medicina. Pontificia Universidad Católica de Chile

2. FONDAP Center for Genome Regulation. Millennium Institute for Integrative Biology (iBio), Departamento de Genética Molecular y Microbiología, Pontificia Universidad Católica de Chile, Santiago, 8331150, Chile.

3. Laboratorio de Microbiología. Servicio de laboratorios Clínicos. Red de Salud UC-CHRISTUS

4. Departamento Enfermedades Infecciosas e Inmunología Pediátricas, Escuela Medicina, Pontificia Universidad Católica de Chile.

$\$$ co-first authors

${ }^{*}$ Corresponding authors to whom correspondence should be addressed:

Rodrigo A. Gutiérrez, PhD

Dept. Molecular Genetics and Microbiology

School of biological Sciences

Pontificia Universidad Católica de Chile

Av. Libertador Bernardo O`Higgins 340

Santiago, Chile

Tel: +56 2 2686-2663; Fax: +56 2 2222-5515

rgutierrez@bio.puc.cl

Patricia García, MD

Dept. Clinical Laboratories

School of Medicine

Pontificia Universidad Católica de Chile

Av. Vicuña Mackenna 4686, 3rd floor

Santiago - Chile.

Tel: +562-23548573; Fax: +562-23548571

pgarciacan@uc.cl 


\begin{abstract}
The technique RT-qPCR for viral RNA detection is the current worldwide strategy used for early detection of the novel coronavirus SARS-CoV-2. RNA extraction is a key pre-analytical step in RT-qPCR, often achieved using commercial kits. However, the magnitude of the COVID-19 pandemic is causing disruptions to the global supply chains used by many diagnostic laboratories to procure the commercial kits required for RNA extraction. Shortage in these essential reagents is even more acute in developing countries with no means to produce kits locally. We sought to find an alternative procedure to replace commercial kits using common reagents found in molecular biology laboratories. Here we report a method for RNA extraction that takes about $40 \mathrm{~min}$ to complete ten samples, and is not more laborious than current commercial RNA extraction kits. We demonstrate that this method can be used to process nasopharyngeal swab samples and yields RT-qPCR results comparable to those obtained with commercial kits. Most importantly, this procedure can be easily implemented in any molecular diagnostic laboratory. Frequent testing is crucial for individual patient management as well as for public health decision making in this pandemic. Implementation of this method could maintain crucial testing going despite commercial kit shortages.
\end{abstract}

Keywords: Coronavirus; SARS-CoV-2; RNA extraction

\title{
Introduction
}

SARS-CoV2, a member of the Coronaviridae family, is the etiological agent of the current COVID-19 pandemic that has generated an international public health emergency. As of May $3^{\text {rd, }} 2020$, the virus has infected more than 3.3 million individuals and killed over 238,000 people worldwide (Situation Report 104 of the World Health Organization). Testing for the presence of the virus is of utmost importance for containment strategies aiming to reduce dissemination of the virus and prescription of appropriate clinical practices for affected patients. However, understanding and managing the full extent of the outbreak has remained a challenge for most countries due to significant bottlenecks imposed by diagnosis ${ }^{1}$.

Early detection of infection by SARS-CoV2 relies on the efficient detection of the viral genome using RT-qPCR. Several RT-qPCR-based tests are being used in clinical settings $^{2}$, and novel approaches are constantly being reported ${ }^{3-10}$. All methods require an RNA extraction step to isolate the viral genetic material before its detection. Unfortunately, RNA extraction has become a serious bottleneck for COVID-19 diagnosis around the world due to shortages in RNA-extraction kits customarily used to process patients samples. This is particularly troublesome in developing countries lacking the infrastructure and capacities to produce these kits locally. Before the kit-era, which contributed to standardize and simplify molecular biology work, several RNA extraction methods were routinely used in research laboratories around the world. RNA isolation 
procedures typically involve three general steps: cell lysis, separation of RNA from other macromolecules such as DNA, proteins, and lipids, followed by RNA concentration. To prevent RNA degradation, cell lysis must be conducted under conditions that inhibit RNase activity, which is abundant in many cellular compartments ${ }^{11,12}$. RNA separation from other macromolecules is often achieved by a combination of $\mathrm{pH}$ and organic solvents, such as phenol/chloroform ${ }^{13-16}$. RNA concentration is most commonly achieved by high salt and isopropanol or ethanol precipitation ${ }^{11,12,17-20}$.

We reviewed the published literature to search for procedures of RNA extraction that could potentially be used to replace commercial kits. Many different protocols and variations have been published over the years that optimize or simplify the RNA extraction process from various types of samples. We tested five types of procedures to identify an efficient procedure for extracting RNA from clinical samples that is compatible with downstream RT-qPCR analysis. Of the procedures evaluated, a simple method based in acid $\mathrm{pH}$ separation of RNA was found the most suitable. It can be carried out in approximately $40 \mathrm{~min}$ for ten samples, and is not more laborious than current methods using commercial kits. This procedure requires reagents and equipment that can be found in any standard molecular biology laboratory, thus avoiding supply chain issues. The resulting RNA can be used to detect SARS-CoV2 by standard RT-qPCR testing protocols with robust results comparable to those obtained using commercial RNAextraction kits.

\section{Results}

Screening of alternative procedures for RNA extraction

For validation of the RNA extraction procedures, the RNase $\mathrm{P}$ target was amplified in a one-step RT-qPCR reaction, as quality control for the extraction method. As shown in Figure 1, three of the five procedures evaluated yielded enough RNA to amplify the target gene, whereas two of them did not. The TRIzol approach was most effective, exhibiting the highest yield when amplifying the human RNase $P$ target (Figure 1). The BSA-based protocol also allowed for amplification of the RNase $\mathrm{P}$ target, albeit with a lower yield and significant variability among replicates (Figure 1). Acid $\mathrm{pH}$-based method also allowed amplification of the RNase $\mathrm{P}$ target, though with lower yields when compared to the TRIzol method (Figure 1). The direct method and high-temperature method did not yield enough RNA to amplify the RNase $P$ gene under our experimental conditions. While TRIzol appears to be the best experimental procedure in terms of yield, it is not easy to use for a diagnostics laboratory setting as it requires a chemical hood for the organic extraction step. Biosafety cabinets class II (BSL-2) necessary for operator protection are not appropriate for working with organic solvents. BSA, TRIzol, and acid $\mathrm{pH}$ procedures provided comparable yields, but the acid $\mathrm{pH}$ method was more consistent among replicates. Based on these considerations, we decided to validate the acid $\mathrm{pH}$ 
method to extract RNA from clinical samples, using High Pure Viral RNA Kit (Roche) as the gold standard.

\section{Validation of the acid pH RNA extraction method in clinical samples}

To validate the acid $\mathrm{pH}$ method of RNA extraction, RT-qPCR using TaqMan probes and primers recommended by the CDC were used ${ }^{21}$. The nucleocapsid viral proteins $\mathrm{N} 1$ and $\mathrm{N} 2$ were amplified as viral targets, and RNase $\mathrm{P}$ was also amplified as a control. We analyzed 50 clinical samples: 22 were positive, 11 were undetermined, and 17 were negative according to RT-qPCR recommended by $C D C^{21}$, using RNA extracted with High Pure Viral RNA Kit (Roche). Undetermined samples are described as having a viral load around the limit of detection (LOD) of the RT-qPCR method that was reported as $10^{0.5}$ RNA copies $/\left.\mu\right|^{21}$. This means that the RT-qPCR method can detect 16 RNA copies per PCR reaction. The PCR test used detects 2 targets of the virus: N1 and N2. The mean $\mathrm{Cq}$ value for $\mathrm{N} 1$ target reported for sets of dilutions that are $\geq 95 \%$ positive is around $36^{21}$. Therefore we analyzed the efficiency of both extraction methods in two different groups of samples: those with $\mathrm{Cq} \mathrm{N} 1 \leq 36$ and those with $\mathrm{Cq} \mathrm{N} 1>36$. The results for the 50 samples are shown in Table 1. For samples with $\mathrm{Cq} \mathrm{N} 1 \leq 36$ there were no differences in $\mathrm{Cq}$ values for N1 and N2 obtained using High Pure Viral RNA Kit (Roche) or the acid $\mathrm{pH}$ method (Figure 2A). In contrast, for samples with $\mathrm{Cq} \mathrm{N1}>36$, Cq values for N1 and N2 were higher for High Pure Viral RNA Kit (Roche) than those obtained with acid $\mathrm{pH}$ method ( $\mathrm{p}=0.026$ and $\mathrm{p}=0.022$ respectively) (Figure 2B). For samples with $\mathrm{Cq}$ $\mathrm{N} 1 \leq 36, \mathrm{Cq}$ values for RNase $\mathrm{P}$ were slightly higher for acid $\mathrm{pH}$ method $(\mathrm{p}=0.021)$, whereas for samples with $\mathrm{Cq} \mathrm{N} 1>36$ there was no significant difference between both methods. The \% of agreement between both methods was calculated considering samples whose report changed from positive, undetermined or negative. In total, 8 samples changed their report. The 17 negative samples were also negative using RNA extracted with the acid $\mathrm{pH}$ method. Out of 22 positive samples, 21 were also positive using RNA extracted with the acid $\mathrm{pH}$ method, whereas one sample was undetermined. Out of 11 undetermined samples analyzed, 4 were still undetermined using RNA extracted with the acid $\mathrm{pH}$ method. However, 3 of them were negative and 4 of them were positive. Agreement for negative samples was 100\%. The percentage of agreement for samples with $\mathrm{Cq} \mathrm{N} 1 \leq 36$ was $89.5 \%$. As expected, the percentage of agreement for samples with $\mathrm{Cq} \mathrm{N} 1>36$ was only $57 \%$.

Importantly, the processing time and laboriousness of the acid-pH method is similar or less than that of High Pure Viral RNA Kit (Roche) method. A detailed scheme of the method is shown in Figure 3.

\section{Discussion}

Here we tested several kit-free RNA extraction methods compatible with RT-qPCR analysis and selected one simple procedure based on RNA extraction using acid $\mathrm{pH}$. We validated this method using 50 clinical samples with results comparable to those 
obtained with commercial kits. There are three key aspects of this method that must be pointed out. First, the acid $\mathrm{pH}$-based methods that we reviewed ${ }^{12,14,22}$ are intended for RNA extraction from tissue, cultured cells, and cell-associated virus. Therefore, the first step of these protocols is centrifugation with subsequent lysis of the cell pellet. However, we need to recover free viral particles in solution, which do not sediment after routine centrifugation at $15,000 \mathrm{~g}$. For this reason we used the uncentrifuged sample directly mixed with lysis buffer, with subsequent precipitation of viral RNA in the whole mix volume. Using uncentrifuged sample is the key step for efficient RNA recovery because when centrifuged sample was used in preliminar tests, $\mathrm{Cq}$ values were much higher than those obtained with High Pure Viral RNA Kit (Roche). Second, the acid pH method uses the anionic detergent Sodium dodecyl sulfate (SDS) that can lyse cells and viral coats through disruption of noncovalent bonds in proteins causing them to lose their native conformation $^{12}$. Third, low $\mathrm{pH}$ and high concentration of salt make possible the selective recovery of RNA. Within the $\mathrm{pH}$ range of 5.5 to 6.0 , RNA degradation is minimized ${ }^{22}$. RNA phosphodiester bond is more stable at acidic than alkaline $\mathrm{pH}$, where it is susceptible to alkaline hydrolysis at $\mathrm{pH}$ greater than $6^{23}$. Acid hydrolysis can only occur at $\mathrm{pH}$ lower than $2^{12,24}$. Moreover, DNA and RNA have different solubility at different $\mathrm{pH}$, mainly due to the 2 ' hydroxyl group of RNA, which increases the polarity of this nucleic acid $^{25,26}$. Therefore, it is essential to adjust the Lysis Buffer to $\mathrm{pH} 5$, as described in Materials and Methods.

It is worth mentioning that all of the samples that changed their report had Cq values that were around the cutoff value of 40 . These changes occurred in both directions, meaning that some Cqs increased and some Cqs decreased. It would have been very clarifying to perform triplicated RNA extractions, in particular for undetermined samples, whose viral load is around the detection limit. Because of the above exposed information we consider the acid $\mathrm{pH}$ method robust and reliable. In fact, it is currently being used in our diagnostic laboratory since the $3^{\text {rd }}$ week of April 2020 for routine detection of SARS-CoV2 in clinical samples.

The RNA extraction procedure with acid $\mathrm{pH}$ described here has many advantages over commercial kits to test for SARS-CoV-2 in the context of the current pandemic. This experimental procedure utilizes low cost reagents and equipment that can be found in standard molecular biology laboratories. The cost of extraction is a critical issue in most clinical laboratories, and the cost of our in-house method is around ten times lower than extraction kits. Moreover, DNase treatment is not necessary because SARS-CoV-2 detection is not altered in the presence of DNA. In fact, residual DNA may serve as the template for RNase $\mathrm{P}$ gene amplification. Because of current environmental concerns, we would also like to highlight the lower plastic contamination generated by this in-house method. Column-based extraction kits use several disposable tubes per sample, columns, bottles of buffer solutions, and plastic bags. Our in-house extraction method is by far, much more environmental friendly; it requires only two Eppendorf tubes per sample. Finally, our in-house method is comparable in hands-on time to commercial kits: it can be carried out in approximately 40 minutes for a set of 10 samples. However, it is 
important to mention that additional care must be taken in handling to avoid crosscontamination between samples.

In conclusion, the RNA extraction procedure with acid $\mathrm{pH}$ described here is an excellent alternative to commercial systems to test for SARS-CoV2. Our results support a new method for RNA extraction from swab samples that can be used to detect SARS-CoV2 by standard RT-qPCR testing protocols. This procedure can be a helpful alternative for laboratories facing supply-chain disruption and commercial kit shortages.

\section{Materials and Methods}

\section{Biological samples}

Two types of biological samples were used. For preliminary evaluation of the RNA extraction methods we used saliva samples obtained from two asymptomatic volunteers. Saliva is routinely collected for the initial assessment of viral infection. Two saliva samples were obtained from each volunteer and at least three independent RNA extractions were performed from each sample, obtaining a minimum of six RNA preparations to test each experimental procedure. For validation of the RNA extraction method selected, we used nasopharyngeal swabs in Universal Transport Medium (UTM). Swabs were obtained from 50 patients that attended the outpatient service of Red Salud UC-CHRISTUS (Santiago, Chile) because of suspected coronavirus infection. Only one sample was obtained per patient: one portion of the sample was extracted using the High Pure Viral RNA Kit (Roche), and another portion of the same sample was extracted using the acid $\mathrm{pH}$ method. Informed consent was obtained from all participants and/or their legal guardians. Samples were processed in the Laboratory of Diagnostic Microbiology of the same institution. All methods were performed in accordance with the relevant guidelines and regulations. All procedures were approved by the Ethics Committee of the Pontificia Universidad Católica de Chile.

\section{RNA extraction methods evaluated}

The following experimental procedures were tested in this study. Saliva samples were centrifuged before taking an aliquot of supernatant for processing as described below.

(1) TRIzol. The standard TRIzol-based method was evaluated ${ }^{9,11,18}$. First, $800 \mu \mathrm{L}$ of TRIzol were added to $200 \mu \mathrm{L}$ of sample and vortexed briefly. Then, $200 \mu \mathrm{L}$ of chloroform were added, vortexed, and centrifuged at $12,000 \mathrm{~g}$ for $10 \mathrm{~min}$ at room temperature. The aqueous phase $(600 \mu \mathrm{L})$ was recovered in a clean tube containing $600 \mu \mathrm{L}$ of isopropanol. The tube was mixed by inversion and incubated at room temperature for $10 \mathrm{~min}$. The tube was then centrifuged at $12,000 \mathrm{~g}$ for $10 \mathrm{~min}$ at $4^{\circ} \mathrm{C}$, and the supernatant was discarded. The pellet was washed with $500 \mu \mathrm{L}$ of $70 \%$ ethanol, centrifuged at $7,500 \mathrm{~g}$ for $5 \mathrm{~min}$ at $4^{\circ} \mathrm{C}$ and the supernatant was discarded. The pellet was dried at room temperature for $10 \mathrm{~min}$ and resuspended in $25 \mu \mathrm{L}$ of RNase-free water by incubating at $37^{\circ} \mathrm{C}$ for $10 \mathrm{~min}$. 
(2) BSA-based method. Previous reports show that BSA has positive effects on RTqPCR results when added to samples in the presence of inhibitors ${ }^{27,28}$. Based on the procedure described by Plante et al. $(2010)^{27}$ and Svec et al. $(2013)^{28}$, a $200 \mu \mathrm{L}$ aliquot sample was centrifuged at $12,000 \mathrm{~g}$ for $30 \mathrm{~s}$ at room temperature. Then, $2.5 \mu \mathrm{L}$ of supernatant were added to $47.5 \mu \mathrm{L}$ of a $1 \mathrm{mg} / \mathrm{mL}$ BSA solution (1:20 ratio), vortexed for $30 \mathrm{~s}$ and kept on ice or at $-80^{\circ} \mathrm{C}$ until further use.

(3) Acid pH-based method. Under acidic $\mathrm{pH}$, RNA can be separated from DNA and other molecules due to the differential polarity given by its hydroxyl groups, which maintains it in solution ${ }^{12,22,25,26,29}$. Based on the methods described by Heath $(1999)^{22}$, Sambrook and Russell (2001) ${ }^{12}$, and Chomczynski and Sacchi (2006) ${ }^{14}, 300 \mu \mathrm{L}$ of pH 5 Lysis Buffer (69,4 mM SDS, $68 \mathrm{mM}$ sodium citrate dihydrate, $132 \mathrm{mM}$ anhydrous citric acid and $10 \mathrm{mM}$ EDTA, then adjust the buffer to $\mathrm{pH}$ 5) were added to $200 \mu \mathrm{L}$ of uncentrifuged sample and mixed by pipetting three times. Then, $150 \mu \mathrm{L}$ of Precipitation Buffer (17 mM sodium citrate dihydrate, $33,3 \mathrm{mM}$ anhydrous citric acid, and $4 \mathrm{M} \mathrm{NaCl}$ ) were added and mixed by inversion 10 times. Samples were incubated on ice for 5 min and centrifuged at $15,000 \mathrm{~g}$ for $3 \mathrm{~min}$ at room temperature. $600 \mu \mathrm{L}$ of the supernatant were transferred to a clean tube containing $600 \mu \mathrm{L}$ of isopropanol and incubated for 10 min at room temperature. A new centrifugation step was made at $15,000 \mathrm{~g}$ for $5 \mathrm{~min}$ at room temperature. The supernatant was removed, and the pellet washed with $300 \mu \mathrm{L}$ of cold $70 \%$ ethanol and centrifuged at $15,000 \mathrm{~g}$ for $3 \mathrm{~min}$ at room temperature. Supernatant was discarded and tubes were inverted in paper towel. The pellet was dried, leaving the tubes open for $10 \mathrm{~min}$. Finally, the pellet was resuspended in $50 \mu \mathrm{L}$ of nuclease-free water pre-warmed at $70^{\circ} \mathrm{C}$.

NOTE: If the buffer is stored for later use, it precipitates at $4^{\circ} \mathrm{C}$, so it needs to be heated for 5 minutes at $60^{\circ} \mathrm{C}$ for its use.

(4) High temperature-based method. Based on the method described by Fomsgaard and Rosenstierne $(2020)^{30}, 50 \mu \mathrm{L}$ of the sample were directly heated at $98^{\circ} \mathrm{C}$ for $5 \mathrm{~min}$ and cooled at $4^{\circ} \mathrm{C}$. Then $19 \mu \mathrm{L}$ of the sample were mixed with $1 \mu \mathrm{L}$ of BSA ( $\left.20 \mathrm{mg} / \mathrm{mL}\right)$ and kept on ice for immediate use or at $-80^{\circ} \mathrm{C}$ for later use.

(5) Direct use of the samples. An aliquot taken from the original sample was directly used to perform RT-qPCR analysis ${ }^{31}$.

The 50 nasopharyngeal swabs used for the validation of the RNA extraction method selected, were extracted using High Pure Viral RNA Kit (Roche) according to instructions provided by the manufacturer. This RNA extraction method was considered as the gold standard for comparison purposes, and It is based in capture of RNA using columns with silica filters. 


\section{$R T$-qPCR analysis}

For preliminary evaluation of RNA extraction procedures, we used RT-qPCR against the human RNAse $P$ gene with primers and a Taqman probe previously described ${ }^{32}$. RP1-F: AGATTTGGACCTGCGAGCG, RP1-R: GAGCGGCTGTCTCCACAAGT, and RP1-probe: TTCTGACCTGAAGGCTCTGCGCG. The RNase $P$ gene is used as an internal control because many copies of it exist in the human genome, and it is readily detectable. The source of RNase $P$ comes from the human cells that are present in every sample used. It is assumed that if human nucleic acids were extracted to detect the human gene RNase $\mathrm{P}$, viral nucleic acids were also successfully extracted. The RNase $\mathrm{P}$ target is also amplified as a quality control for the extraction method and to corroborate the absence of PCR-inhibitors in the sample.

For RT-qPCR $5 \mu \mathrm{L}$ of RNA from saliva samples, $2 \mu \mathrm{L}$ of RNase-Free water, $1 \mu \mathrm{L}$ of each RNase $P$ primer, $1 \mu \mathrm{L}$ of TaqMan RNase $\mathrm{P}$ probe and $10 \mu \mathrm{L}$ of $2 \mathrm{X}$ TaqMan Fast Universal PCR Master Mix (Applied Biosystems), were used in a final reaction volume of $20 \mu \mathrm{L}$ performed in a StepOnePlus Real-Time PCR System (Applied Biosystems).

For validation of the selected RNA extraction procedure, RT-qPCR using Taqman probes and primers recommended by the CDC was used ${ }^{21}$. Two viral targets were amplified: the nucleocapsid viral proteins $\mathrm{N} 1$ and $\mathrm{N} 2$. Primers and probe for $\mathrm{N} 1$ were N1-F: GACCCCAAAATCAGCGAAAT, N1-R: TCTGGTTACTGCCAGTTGAATCTG, and N1probe: FAM-ACCCCGCATTACGTTTGGTGGACC-BHQ1. Primers and probe for N2 were N2-F: TTACAAACATTGGCCGCAAA, N2-R: GCGCGACATTCCGAAGAA, and N2probe: FAM-ACAATTTGCCCCCAGCGCTTCAG-BHQ1. Primers and probe for RNase $P$ were RP2-F: AGATTTGGACCTGCGAGCG, RP2-R: GAGCGGCTGTCTCCACAAGT, and RP2-probe: FAM-TTCTGACCTGAAGGCTCTGCGCG-BHQ1. A one-step RT-qPCR reaction was performed in a StepOnePlus Real-Time PCR System (Applied Biosystems). Cutoff points for $\mathrm{Cq}$ values (Cycle of quantification, or Cycle Threshold) required to decide whether a result is COVID-19 positive or negative were those specified by CDC as follows. To report a positive result, both viral targets $\mathrm{N} 1$ and $\mathrm{N} 2$ must be $\mathrm{Cq}<40$. To report a negative result both viral targets must be $\mathrm{Cq} \geq 40$. If one of the viral targets is $\mathrm{Cq}<40$ and the other is $\mathrm{Cq} \geq 40$, the result must be reported as undetermined. The RNase $P$ target must be $\mathrm{Cq} \leq 35$.

\section{Statistical analysis}

Mean $\mathrm{Cq}$ values obtained through both methods for each target gene were analyzed in pairwise comparisons using a paired Student's t-test. The analysis was performed using GraphPad Prism 8 software. 


\section{References}

1 Ladha, A., Joung, J., Abudayyeh, O., Gootenberg, J. \& Zhang, F. A 5-min RNA preparation method for COVID-19 detection with RT-qPCR. v.20200405 (2020). <https://static1.squarespace.com/static/5b7c640be2ccd1703a3da4d3/t/5e8bcd0923fb224 b2f3b1356/1586220297644/Ladha+et+al+-+RNA+QE+Extraction.pdf>.

2 FDA. Coronavirus COVID-19 Diagnostic Tests and Shortages, $<$ https://www.fda.gov/medical-devices/emergency-situations-medical-devices/emergencyuse-authorizations\#covid19ivd > (2020).

3 Broughton, J. P. et al. CRISPR-Cas12-based detection of SARS-CoV-2. Nature Biotechnology, doi:10.1038/s41587-020-0513-4 (2020).

4 Cordes, A. K. \& Heim, A. Rapid random access detection of the novel SARS-coronavirus2 (SARS-CoV-2, previously 2019-nCoV) using an open access protocol for the Panther Fusion. Journal of clinical virology : the official publication of the Pan American Society for Clinical Virology 125, 104305, doi:10.1016/j.jcv.2020.104305 (2020).

5 Corman, V. M. et al. Detection of 2019 novel coronavirus (2019-nCoV) by real-time RTPCR. Euro Surveill 25, 2000045, doi:10.2807/1560-7917.ES.2020.25.3.2000045 (2020).

6 Pfefferle, S., Reucher, S., Nörz, D. \& Lütgehetmann, M. Evaluation of a quantitative RTPCR assay for the detection of the emerging coronavirus SARS-CoV-2 using a high throughput system. Euro Surveill 25, doi:10.2807/1560-7917.es.2020.25.9.2000152 (2020).

7 To, K. K. et al. Consistent detection of 2019 novel coronavirus in saliva. Clinical infectious diseases : an official publication of the Infectious Diseases Society of America, doi:10.1093/cid/ciaa149 (2020).

8 Wang, W. et al. Detection of SARS-CoV-2 in Different Types of Clinical Specimens. Jama, doi:10.1001/jama.2020.3786 (2020).

9 Won, J. et al. Development of a Laboratory-safe and Low-cost Detection Protocol for SARS-CoV-2 of the Coronavirus Disease 2019 (COVID-19). Experimental neurobiology, doi:10.5607/en20009 (2020).

10 Zhang, F., Abudayyeh, O. \& Gootenberg, J. A protocol for detection of COVID-19 using CRISPR diagnostics. v.20200321 (2020).

$<$ https://www.broadinstitute.org/files/publications/special/COVID19\%20detection\%20(updated).pdf >.

11 Nilsen, T. W. The fundamentals of RNA purification. Cold Spring Harbor protocols 2013, 618-624, doi:10.1101/pdb.top075838 (2013).

12 Sambrook, J. \& Russell, D. Molecular cloning: a laboratory manual. 3rd edn, (Cold Spring Harbor Laboratory, 2001).

13 Chomczynski, P. \& Sacchi, N. Single-step method of RNA isolation by acid guanidinium thiocyanate-phenol-chloroform extraction. Analytical biochemistry 162, 156-159, doi:10.1006/abio.1987.9999 (1987).

14 Chomczynski, P. \& Sacchi, N. The single-step method of RNA isolation by acid guanidinium thiocyanate-phenol-chloroform extraction: twenty-something years on. Nature protocols 1, 581-585, doi:10.1038/nprot.2006.83 (2006).

15 Mullegama, S. V. et al. Nucleic Acid Extraction from Human Biological Samples. Methods in molecular biology (Clifton, N.J.) 1897, 359-383, doi:10.1007/978-1-4939-8935-5_30 (2019).

16 Puissant, C. \& Houdebine, L. M. An improvement of the single-step method of RNA isolation by acid guanidinium thiocyanate-phenol-chloroform extraction. BioTechniques 8 , 148-149 (1990).

17 Chirgwin, J. M., Przybyla, A. E., MacDonald, R. J. \& Rutter, W. J. Isolation of biologically active ribonucleic acid from sources enriched in ribonuclease. Biochemistry 18, 52945299, doi:10.1021/bi00591a005 (1979). 
18 Rio, D. C., Ares, M., Jr., Hannon, G. J. \& Nilsen, T. W. Ethanol precipitation of RNA and the use of carriers. Cold Spring Harbor protocols 2010, pdb.prot5440, doi:10.1101/pdb.prot5440 (2010).

19 Walker, S. E. \& Lorsch, J. RNA purification--precipitation methods. Methods in enzymology 530, 337-343, doi:10.1016/b978-0-12-420037-1.00019-1 (2013).

20 Zolfaghari, R., Chen, X. \& Fisher, E. A. Simple method for extracting RNA from cultured cells and tissue with guanidine salts. Clinical chemistry 39, 1408-1411 (1993).

21 CDC. Research Use Only 2019-Novel Coronavirus (2019-nCoV) Real-time RT-PCR Primer and Probe Information, <https://www.cdc.gov/coronavirus/2019-ncov/lab/rt-pcrpanel-primer-probes.html> (2020).

22 Heath, E. Low pH RNA isolation reagents, method, and kit. USA patent (1999).

23 Jarvinen, P., Oivanen, M. \& Lonnberg, H. Interconversion and phosphoester hydrolysis of 2',5'- and 3',5'-dinucleoside monophosphates: kinetics and mechanisms. The Journal of Organic Chemistry 56, 5396-5401, doi:10.1021/j000018a037 (1991).

24 Bernhardt, H. S. \& Tate, W. P. Primordial soup or vinaigrette: did the RNA world evolve at acidic $\mathrm{pH}$ ? Biology direct 7, 4, doi:10.1186/1745-6150-7-4 (2012).

25 Lemire, K. A., Rodriguez, Y. Y. \& Mclntosh, M. T. Alkaline hydrolysis to remove potentially infectious viral RNA contaminants from DNA. Virology Journal 13, 88, doi:10.1186/s12985-016-0552-0 (2016).

26 Velikyan, I., Acharya, S., Trifonova, A., Földesi, A. \& Chattopadhyaya, J. The pK(a)'s of 2'-hydroxyl group in nucleosides and nucleotides. Journal of the American Chemical Society 123, 2893-2894, doi:10.1021/ja0036312 (2001).

27 Plante, D. et al. The use of bovine serum albumin to improve the RT-qPCR detection of foodborne viruses rinsed from vegetable surfaces. Letters in applied microbiology $\mathbf{5 2}$, 239-244, doi:10.1111/j.1472-765X.2010.02989.x (2011).

28 Svec, D. et al. Direct cell lysis for single-cell gene expression profiling. Front Oncol 3, 274-274, doi:10.3389/fonc.2013.00274 (2013).

29 Noonberg, S. B., Scott, G. K. \& Benz, C. C. Effect of pH on RNA degradation during guanidinium extraction. BioTechniques 19, 731-733 (1995).

30 Fomsgaard, A. S. \& Rosenstierne, M. W. An alternative workflow for molecular detection of SARS-CoV-2 - escape from the NA extraction kit-shortage, Copenhagen, Denmark, March 2020. Euro Surveill 25, doi:10.2807/1560-7917.es.2020.25.14.2000398 (2020).

31 Beltrán-Pavez, C. et al. SARS-CoV-2 detection from nasopharyngeal swab samples without RNA extraction. bioRxiv, 2020.2003.2028.013508, doi:10.1101/2020.03.28.013508 (2020).

32 Waggoner, J. J. et al. Development of an internally controlled real-time reverse transcriptase PCR assay for pan-dengue virus detection and comparison of four molecular dengue virus detection assays. Journal of clinical microbiology 51, 2172-2181, doi:10.1128/jcm.00548-13 (2013).

\section{Acknowledgments}

We would like to acknowledge people that contributed with helpful discussions and critical comments that helped us along the way, especially Professor Francisco Melo and Professor Marcelo López-Lastra. We would like to also thank Maite Salazar and Laura Delgado for helping with language edits. We would like to express our gratefulness to technicians of the Laboratory of Diagnostic Microbiology, Sandra Prado and Javier Hernández, for all their help with technicals aspects of this work. 


\section{Author Contributions}

AW performed experimental work, data analysis, figure composition, and manuscript writing. $\mathrm{AC}, \mathrm{CIH}$, and VS did experimental work, data analysis, and figure composition. GA, LL, performed a literature search and manuscript writing. CM, ML, SS, AMG, and TQ contributed to experimental design and critical data analysis. SH, ER, MF, performed a literature search and defined protocols for testing. RAG and PG performed the literature search, experimental design, data analysis, and manuscript writing. They co-supervised this project. All authors reviewed the manuscript.

\section{Additional Information}

The authors declare no competing interests.

\section{Funding}

This work was funded by intramural funds provided by the Faculty of Biological Sciences, Faculty of Medicine, and Vicerrector's office for Research at the host institution. Research in R.A.G.'s laboratory is also supported by Millenium Institute for Integrative Biology - iBio (Iniciativa Científica Milenio - MINECON), Fondo de Desarrollo de Áreas Prioritarias (FONDAP) Center for Genome Regulation (15090007) and Fondo Nacional de Desarrollo Científico y Tecnológico (FONDECYT, 1180759). 


\section{Figures}

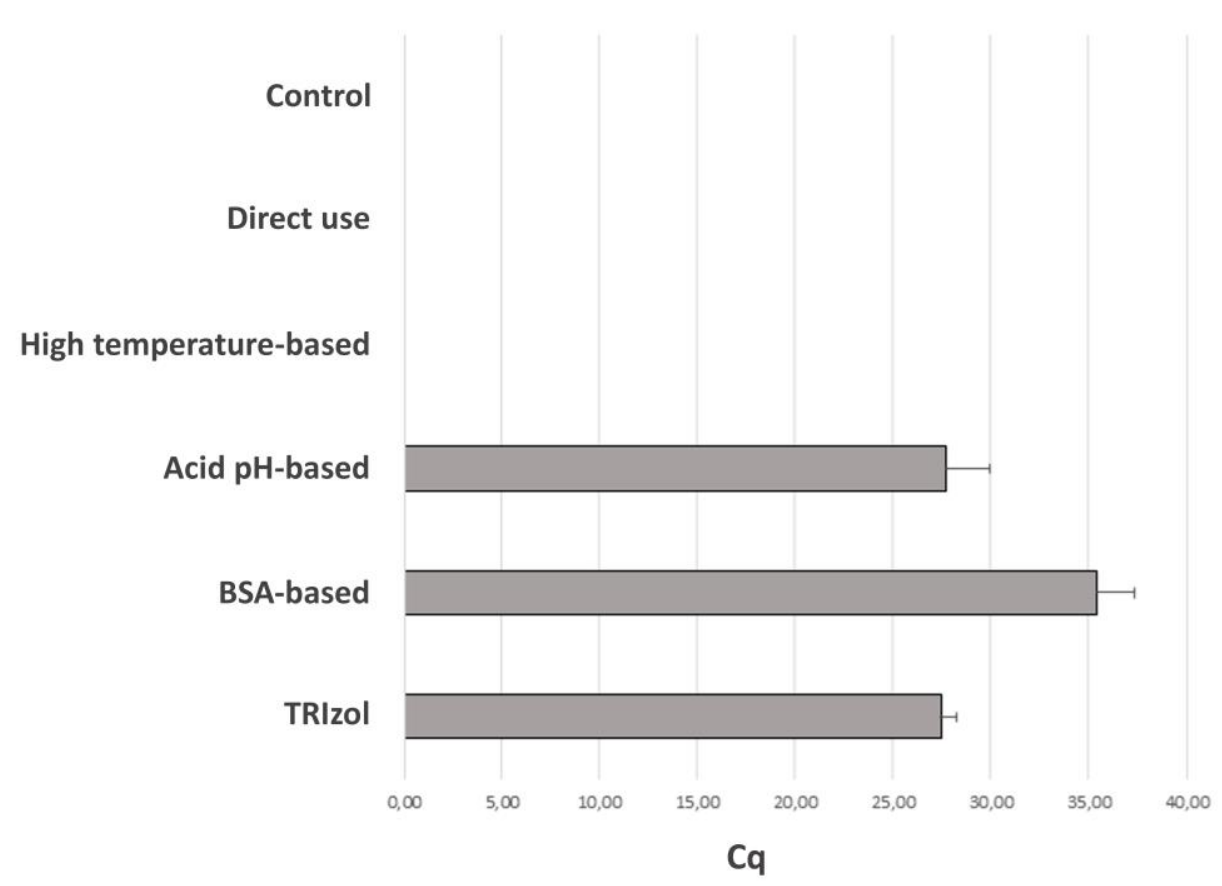

Figure 1. Quantitative assessment of performance for selected RNA extraction methods. $\mathrm{Cq}$ values obtained by RT-qPCR with 45 cycles using TaqMan probe and primers against RNase P gene in saliva samples for TRIzol (27.39+/- 0.34), BSA-based (35.3 +/- 0.79), acid pH-based (27.68 +/- 0.90), high temperature-based (n.d.) and direct (n.d.) methods. n.d.; not determined (no Cq reported). Control corresponds to a negative control with water instead of template. Bars show mean plus standard deviation of the mean for two biological and three technical replicates each (6 measurements). 

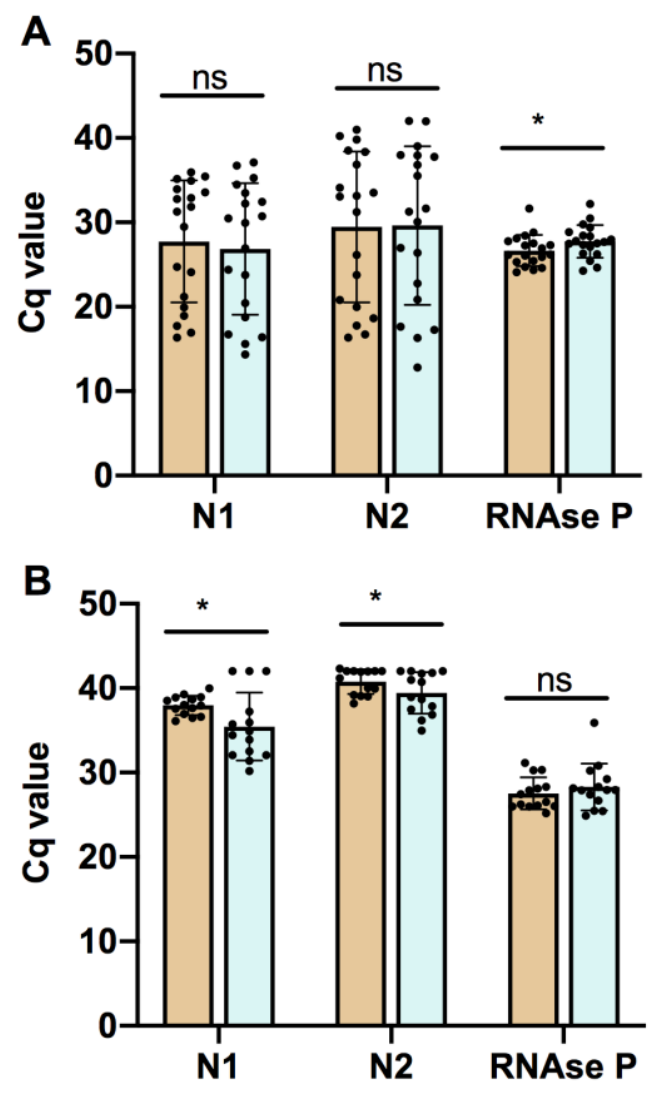

Figure 2. The acid-pH method provides comparable results to commercial kits in clinical samples. Bars represent the mean +/- standard deviation $\mathrm{Cq}$ values for each RT-qPCR target gene N1, N2, and RNase $\mathrm{P}$, for samples with $\mathrm{Cq} N 1 \leq 36$ (A) and with $\mathrm{Cq} N 1>36$ (B). Each dot represents one sample. Orange bars show results obtained with High Pure Viral RNA Kit (Roche). Blue bars show results obtained with the acid pH method. Pairwise comparisons of mean $\mathrm{Cq}$ values for each target gene were done using a two-tailed paired Student's t-test, with a confidence level of $95 \%$. 'ns' means no statistically significant differences. 

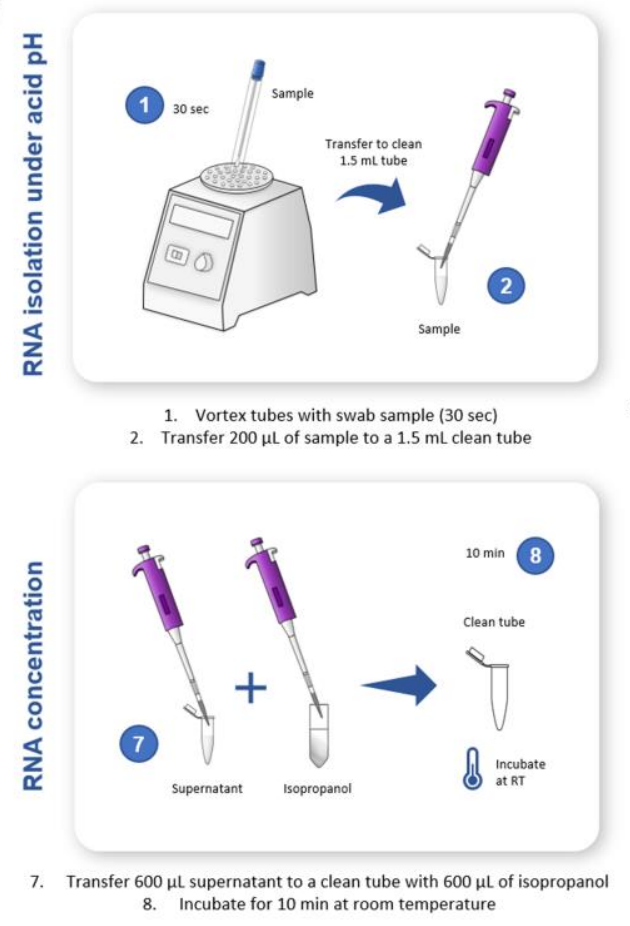

8. Incubate for $10 \mathrm{~min}$ at room temperature

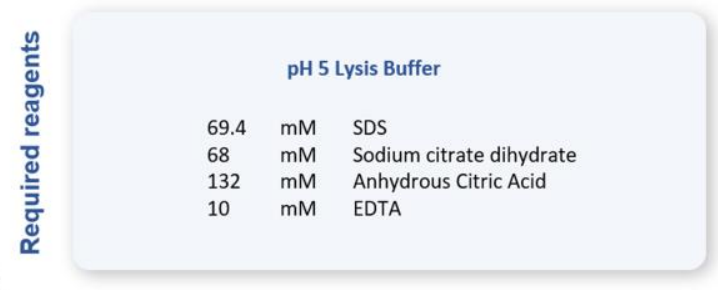

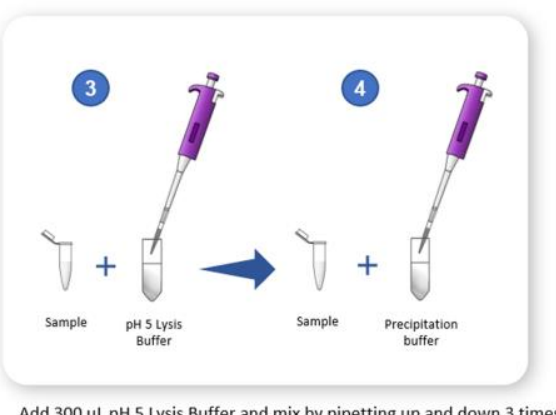

Add $300 \mu \mathrm{L}$ pH 5 Lysis Buffer and mix by pipetting up and down 3 times 4. Add $150 \mu \mathrm{L}$. Precipitation Buffer and mix by inversion 10 times

(9) $\sin _{\text {min }}$
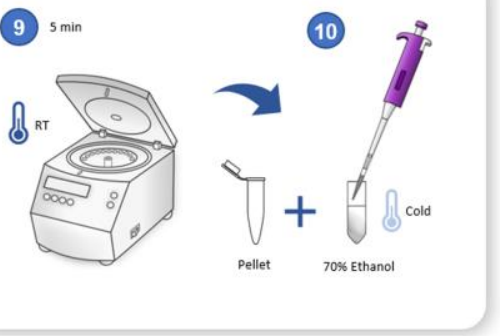
9. Centrifuge at $15000 \mathrm{~g}$ for $5 \mathrm{~min}$ at room temperature
10. Discard supernatant by inversion and wash with 300 $\mu \mathrm{L}$ of cold $70 \%$ ethanol

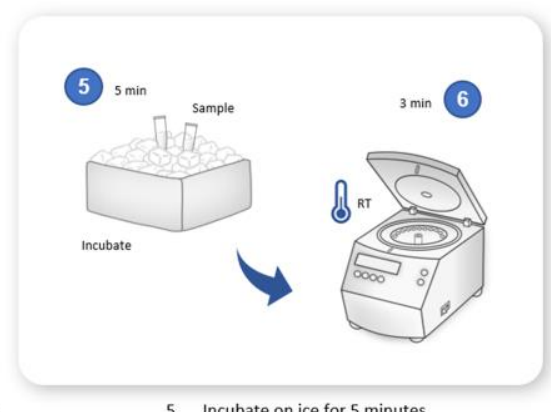

5. Incubate on ice for 5 minutes
6. Centrifuge at $15000 \mathrm{~g}$ for $3 \mathrm{~min}$ at room temperature

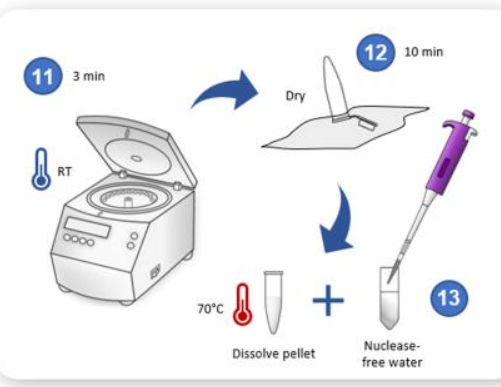

11. Centrifuge at $15000 \mathrm{~g}$ for $3 \mathrm{~min}$ at room temperature 12. Discard supernatant and dry on a paper towel for $10 \mathrm{~min}$ 13. Dissolve pellet in $50 \mu \mathrm{L}$ nuclease-free water at $70^{\circ} \mathrm{C}$

Figure 3. Schematic diagram of the validated acid-pH method for RNA extraction compatible with SARS-CoV2 RT-PCR testing. Steps carried out in the acid pH RNA extraction protocol. 
Table 1. Comparative Cq data for the two RNA extraction methods tested.

\begin{tabular}{|c|c|c|c|c|c|c|c|c|c|}
\hline & \multicolumn{4}{|c|}{ Commercial kit } & \multicolumn{5}{|c|}{ Acid $\mathrm{pH}$ extraction method } \\
\hline & & N1 & $\mathrm{N} 2$ & RNase & Report & N1 & N2 & RNase & Report \\
\hline \multirow{19}{*}{$\mathrm{Cq} \mathrm{N} 1 \leq 36$} & 3410 & 16,37 & 16,34 & 26,06 & positive & 15,62 & 16,31 & 27,96 & positive \\
\hline & 3911 & 16,92 & 17,76 & 24,34 & positive & 16,38 & 17,26 & 25,42 & positive \\
\hline & 3976 & 17,74 & 19,97 & 28,42 & positive & 16,72 & 17,66 & 28,43 & positive \\
\hline & $2859^{*}$ & 18,93 & 16,72 & 31,64 & positive & 14,35 & 12,82 & 27,12 & positive \\
\hline & 3865 & 19,93 & 20,82 & 26,18 & positive & 18,78 & 20,85 & 27,37 & positive \\
\hline & 3959 & 21,17 & 18,65 & 27,53 & positive & 20,43 & 22,79 & 30,47 & positive \\
\hline & 3426 & 24,12 & 26,16 & 24,74 & positive & 24,4 & 26,4 & 24,26 & positive \\
\hline & $3211^{*}$ & 24,72 & 23,76 & 24,62 & positive & 23,79 & 26,99 & 27,49 & positive \\
\hline & 4254 & 29,46 & 31,21 & 24,11 & positive & 30,74 & 31,29 & 24,63 & positive \\
\hline & 3876 & 31,26 & 33,15 & 26,93 & positive & 30,49 & 35,51 & 27,82 & positive \\
\hline & 4210 & 31,85 & 38,51 & 25,31 & positive & 34,49 & 39,01 & 28,84 & positive \\
\hline & 4146 & 32,76 & 34,12 & 28,1 & positive & 29,94 & 31,65 & 27,51 & positive \\
\hline & 3945 & 32,89 & 33,5 & 27,28 & positive & 32,45 & 37,75 & 27,68 & positive \\
\hline & 3958 & 33,58 & 33,05 & 25,42 & positive & 35,28 & 37,97 & 28,37 & positive \\
\hline & 3231 & 33,93 & 40,97 & 27,3 & undetermined & 32,24 & 36,81 & 29,4 & positive \\
\hline & 3831 & 34,93 & 40,21 & 27,75 & undetermined & 37,09 & $\underline{42}$ & 29,76 & undetermined \\
\hline & 3879 & 35,14 & 36,84 & 25,89 & positive & 33,49 & 37,92 & 26,24 & positive \\
\hline & 3413 & 35,45 & 38,36 & 26,13 & positive & 26,93 & 30,07 & 26,32 & positive \\
\hline & $2882^{*}$ & 35,92 & 39,8 & 28,82 & positive & 36,73 & 41,97 & 32,17 & undetermined \\
\hline \multirow{14}{*}{$\mathrm{Cq} \mathrm{N} 1>36$} & 3880 & 36,09 & 39,02 & 27,42 & positive & 34,91 & 41,8 & 27,92 & positive \\
\hline & 3965 & 36,47 & 39,95 & 25,96 & positive & 34,43 & 38,95 & 26,68 & positive \\
\hline & 3285 & 36,61 & 40,03 & 26 & undetermined & 32,06 & 37,47 & 27,89 & positive \\
\hline & 3409 & 38,68 & 39,06 & 25,2 & positive & 31,4 & 34,96 & 25,44 & positive \\
\hline & 3474 & 36,92 & $\underline{42}$ & 28,33 & undetermined & 35,93 & 41,71 & 28,14 & undetermined \\
\hline & $2776^{*}$ & 37,57 & 38,19 & 27,91 & positive & 30,18 & 36,18 & 27,92 & positive \\
\hline & 3298 & 37,64 & $\underline{42}$ & 26,22 & undetermined & 32,07 & 36,86 & 35,89 & positive \\
\hline & $3197^{*}$ & 37,93 & 41,99 & 25,98 & undetermined & $\underline{42}$ & $\underline{42}$ & 25,48 & negative \\
\hline & $2867^{*}$ & 38,51 & 39,18 & 26,1 & positive & 33,91 & 37,86 & 27,41 & positive \\
\hline & 3471 & 38,00 & 41,94 & 30,3 & undetermined & 35,72 & 40,73 & 29,21 & undetermined \\
\hline & 3479 & 38,91 & $\underline{42}$ & 30,28 & undetermined & 37,22 & 40,97 & 30,24 & undetermined \\
\hline & $2946 *$ & 38,95 & 42,31 & 28,11 & undetermined & $\underline{42}$ & $\underline{42}$ & 30,8 & negative \\
\hline & $2815^{*}$ & 39,25 & 41,2 & 31,14 & undetermined & 32,52 & 38,67 & 28,32 & positive \\
\hline & $2943 *$ & 39,96 & $\underline{42}$ & 26,52 & undetermined & $\underline{42}$ & $\underline{42}$ & 24,91 & negative \\
\hline \multirow{15}{*}{ Cq N1 >40 } & 2517 & $\underline{42}$ & $\underline{42}$ & 22,61 & Negative & $\underline{42}$ & $\underline{42}$ & 26,55 & negative \\
\hline & 2518 & $\underline{42}$ & $\underline{42}$ & 25,98 & Negative & $\underline{42}$ & $\underline{42}$ & 33,63 & negative \\
\hline & $2927^{*}$ & $\underline{42}$ & $\underline{42}$ & 29,55 & negative & $\underline{42}$ & $\underline{42}$ & 27,76 & negative \\
\hline & 3877 & $\underline{42}$ & $\underline{42}$ & 29,21 & negative & $\underline{42}$ & $\underline{42}$ & 28,97 & negative \\
\hline & 3878 & $\underline{42}$ & $\underline{42}$ & 27,11 & negative & $\underline{42}$ & $\underline{42}$ & 26,31 & negative \\
\hline & 3881 & $\underline{42}$ & $\underline{42}$ & 26,07 & negative & $\underline{42}$ & $\underline{42}$ & 25,95 & negative \\
\hline & 3882 & $\underline{42}$ & $\underline{42}$ & 25,13 & negative & $\underline{42}$ & $\underline{42}$ & 24,19 & negative \\
\hline & 3973 & $\underline{42}$ & $\underline{42}$ & 29,03 & negative & $\underline{42}$ & $\underline{42}$ & 30,24 & negative \\
\hline & 3960 & $\underline{42}$ & $\underline{42}$ & 25,8 & negative & $\underline{42}$ & $\underline{42}$ & 24,94 & negative \\
\hline & 3961 & $\underline{42}$ & $\underline{42}$ & 29,96 & negative & $\underline{42}$ & $\underline{42}$ & 31,62 & negative \\
\hline & 3962 & $\underline{42}$ & $\underline{42}$ & 29,15 & negative & $\underline{42}$ & $\underline{42}$ & 33,11 & negative \\
\hline & 3963 & $\underline{42}$ & $\underline{42}$ & 26,82 & negative & $\underline{42}$ & $\underline{42}$ & 28,16 & negative \\
\hline & 3964 & $\underline{42}$ & $\underline{42}$ & 29,18 & negative & $\underline{42}$ & $\underline{42}$ & 32,58 & negative \\
\hline & 4170 & $\underline{42}$ & $\underline{42}$ & 29,85 & negative & $\underline{42}$ & $\underline{42}$ & 34,6 & negative \\
\hline & 4173 & $\underline{42}$ & 42 & 27,25 & negative & 42 & 42 & 32,82 & negative \\
\hline
\end{tabular}


bioRxiv preprint doi: https://doi.org/10.1101/2020.05.07.083048; this version posted September 21, 2020. The copyright holder for this preprint (which was not certified by peer review) is the author/funder, who has granted bioRxiv a license to display the preprint in perpetuity. It is made available under aCC-BY-NC 4.0 International license.

\begin{tabular}{lllllllll}
\hline 4174 & $\underline{42}$ & $\underline{42}$ & 28,4 & negative & $\underline{42}$ & $\underline{42}$ & 32,92 & negative \\
4175 & $\underline{42}$ & $\underline{42}$ & 29,63 & negative & $\underline{42}$ & $\underline{42}$ & 33,72 & negative \\
\hline
\end{tabular}

The * denotes extraction was done with $600 \mu \mathrm{L}$ of Lysis Buffer. All other samples were extracted using 300 $\mu \mathrm{L}$ as described in Materials and Methods. Bold letters show samples that changed their report's results. A $\mathrm{Cq}$ value of 42 was considered for those negative q-PCR results where no $\mathrm{Cq}$ value is provided in order to calculate the difference between Cq values. 